\title{
IMPRESSO: DO FOLHETO AO COMPUTADOR
}

\author{
Julieta Beatriz Ramos Desaulniers*
}

SÍNTESE - O texto discute questões de cunho teórico-metodológico relativas à utilização do impresso (textos escolares e não escolares) como fonte para a História da Educação $e$, conseqüentemente, para se reconstruir a produção do social. Apresenta-se a problemática de pesquisa que subsidia investigações em andamento, visando instigar a elaboração de um possivel referencial aos objetos construidos sobre textos produzidos por instituições e organizações sociais, em países ibero-americanos e demais países, enquanto meio de formação do cidadão instaurada, em especial, durante 0 século xx. Destaca-se a necessidade de se explicitarem as condições de produção do discurso científico e a importância de análises comparadas, a fim de se apreender a materialidade $\mathrm{e} o$ significado de tal processo para a sociedade como um todo, principalmente neste final de milênio.

PALAVRAS-CHAVE - impresso, formação do cidadão, discurso científico.
ABSTRACT - The text discusses theoreticalmethodological questions related to the use of printed matter (school and non-school texts) as a source for the history of education and, consequently, for the reconstruction of the production of the social context. It presents the research problem that motivates ongoing investigations, which aim toward the elaboration of a possible referential to the objects construed on texts produced by social institutions and organizations, both in Iberian-American and in other countries, as a means of citizen formation which was established especially in the $20^{\text {th }}$ century. The text points out the need to explain the conditions of scientific discourse production and the importance of compared analyses, so that one can apprehend the materiality and the meaning of such a process for society as a whole, especially now, at the end of the century. KEY WORDS - printed matter, formation of citizens, scientific discourse.

Desde o surgimento da técnica da impressão, os seus meios, saberes e processos envolvem e condicionam cada vez mais a formação dos agentes sociais. Nesta virada de século, o acentuado aprimoramento obtido através da informatização desses meios que intensificam a sua utilização permite afirmar que tal dispositivo assume uma posição privilegiada na construção de identidades sociais, especialmente nas sociedades em que predomina a cultura digital.

* Professora e pesquisadora junto â Faquldade de Filosofia e Ciências Humanas (FFCH) e Programas de Pós-Graduaçāo em Educação, Serviç̣o Social e Administração da PUCRS.

\begin{tabular}{l|l|l|l|l|l|} 
VERITAS & Porto Alegre & v. 43 & $\mathrm{n}^{2}$ especial & Dezembro 1998 & p. 141-150 \\
\hline
\end{tabular}


Pretende-se propor alguns elementos que podem contribuir ao desenvolvimento de um possivel referencial teórico-metodológico, capaz de articular estudos e pesquisas que visam captar a evolução e o significado do impresso, um dos tipos de mídia tão valorizados desde a Revolução Industrial. Procura-se igualmente investigar como esse veículo tem estimulado e mesmo garantido a formação do cidadão, instaurada em instituições e organizações sociais (escolares e não escolares), em diversos países ibero-americanos, em especial, no decorrer do séculos $\mathrm{XX}{ }^{1}$

Para se apreender a materialidade dessa dinâmica, que se desenvolve tanto no interior desses lugares $^{2}$ (instituições e/ou organizações sociais) quanto nas demais esferas sociais em que estão inseridos, faz-se necessária uma análise comparada que considere as relações de disputa pelo poder, desencadeadas entre os agentes dos vários campos do espaço social inseridos nesses processos.

Inicialmente, tece-se alguns comentários sobre questões teóricometodológicas relativas à utilização do impresso (textos escolares e não escolares) como fonte para a História da Educação e, conseqüentemente, para se reconstruir a produção do social. Em seguida, apresenta-se a problemática de pesquisa que fundamenta as investigações em andamento junto à linha de pesquisa Formação, Trabalho e Instituição, como um possivel referencial aos objetos construídos em torno de textos produzidos pela escola ou por agentes sociais associados direta ou indiretamente aos interesses desses lugares, aqui denominados de impressos. No final, procura-se destacar o significado e a importância da análise de tal fenômeno, para a sociedade como um todo, nesta virada de milênio.

\section{1 - Algumas questões preliminares}

Exponho, a seguir, algumas considerações iniciais relativas a elementos que podem contribuir para o debate em torno das questões mencionadas acima, baseadas em pressupostos que fundamentam a pesquisa enquanto ato que busca rigor científico, não podendo então prescindir de algumas condições, dentre elas a necessidade de se explicitarem as condições de produção do discurso científico.

Na perspectiva do novo espírito que orienta a ciência, o fenômeno investigado é concebido como um tecido de relações a ser reconstituído a partir da construção de uma problemática de pesquisa, baseada numa perspectiva teórica que resulta da dialética entre racional e real e materializa-se, no decorrer do processo investigativo, através de um conjunto de procedimentos metodológicos.

ij

1 Algumas das idéias expostas nesse texto foram apresentadas em eventos cientificos que se relacionavam diretamente com tais questões: - Avatares del pasado y tendencias actuales - Segundo Seminário Intemacional sobre textos escolares en Theroamérica, em Buenos Aires, de 11 a 14/11/1997; - III Encontro da Associação de Pesquisadores em História da Educação (ASPHE), na Universidade de Santa Maria, 23 e 24/04/1998; - xX Congresso Intemacional de História da Educação (ISCHE), em Bruxelas, de 15 a 18/08/1998.

2 A categoria lugar está sendo aqui empregada de acordo com a perspectiva de VIÑO FRAGO, Antonio. "Del espacio escolar y la escuela como lugar: propuestas y questiones". In: Revista Interuniversitária Historia de la Educación, Salamanca, n. 12-13, p. 17-19, 1993-1994. 


\section{2 - As condições de produção do discurso científico}

Cabe então indagar aqui em que consiste a explicitação das condições em que se produz 0 discurso científico. $\mathrm{Na}$ realidade, esse procedimento implica $\mathrm{O}$ esclarecimento de várias questões intimamente relacionadas entre si, de ordem epistemológica e teórico-metodológicas, tais como: o que é e como se produz ciência; concepções de fenômeno social e objeto de pesquisa; relação entre teoria, pesquisa, método, dado, etc.

As decisões de cunho teórico-metodológico relativas a impresso enquanto categoria de análise de textos escolares e não escolares estão condicionadas principalmente às concepções quanto às questões referidas acima. Sendo assim, é indispensável objetivar o mais possivel tais problemas, a fim de se estabelecer o minímo de consenso em torno desses aspectos, já que se referem a conđições que tendem a vitalizar a dinâmica das investigações das pesquisas empreendidas em torno de tal objeto.

\section{1 - O impresso enquanto texto escolar e não escolar?}

Os critérios de classificação a serem utilizados para se estabelecer os tipos de textos considerados fontes de pesquisa resultam, sem dúvida, de uma opção de caráter epistemológico, objetivada ou não pelos pesquisadores e associada às suas concepções referentes a fenômeno, teoria e método, dentre outras noções que envolvem igualmente procedimentos e categorias de análise.

Partindo-se do pressuposto de que todo pesquisador tem interesse em realizar um trabalho frutifero e promissor ao contexto social onde os objetos de pesquisa por ele selecionados estão inseridos, faz-se necessário então apreender o fenômeno em sua complexidade e, em decorrência disso, admitir que o texto impresso enquanto meio pedagógico não constitui, nem se encerra tão somente no ambiente escolar.

Sendo assim, parece mais apropriado atribuir a denominação mais genérica de impresso a todo texto (escolar e não escolar) utilizado como veículo de formação e de informação, seja ele de uso restrito ao meio escolar ou tenha uma distribuição e circulação mais amplas, atingindo a comunidade em geral. Isso porque o que distingue e configura a escola enquanto lugar voltado à formação do trabalhador e cidadão, bem como qualquer outra esfera social, é a teia de relações que resulta de inúmeras iniciativas e estratégias que envolvem tanto os agentes que atuam no interior de uma instituição ou organização quanto os demais representantes de outros campos do espaço social que com ela interagem.

Por isso, a categonia impresso pode oferecer possibilidades de análises mais amplas, já que dispõe de um potencial capaz de mediatizar as relações desencadeadas no interior da escola ou em outro lugar privilegiado de formação, podendo igualmente representar e materializar os laços que se estabelecem com as demais esferas sociais que se relacionam com a instituição em análise. Assim, o'impresso constitui em um objeto de investigação científica por privilegiar toda tessitura do fenômeno, pois qualquer fato isolado, em si, não possui sentido. 
Enfim, vale destacar que todos os argumentos utilizados para validar a categorização relativa a impresso têm seu fundamento em pressupostos epistemológicos que busquem formas de explicitação para se assegurar o rigor à pesquisa.

\section{2 - Por que construir o objeto de pesquisa?}

Em que consiste a relação entre teoria, método e dados?

Outro ponto crucial no tocante à produção do discurso científico e que compromete diretamente $\mathrm{o}$ andamento das pesquisas refere-se à necessidade de se explicitar a construção do objeto de pesquisa em torno do impresso - uma das fontes privilegiadas para se reconstituir a produção do social. Como qualquer fonte histórica, o impresso não tem como fornecer de imediato os registros que o constituem e, para que isso ocorra, será indispensável instaurar um processo metódico capaz de inqueri-lo e, assim, captar os elementos menos aparentes que nele estão contidos.

Como todo conhecimento é resposta a uma pergunta, é imprescindível a formulação de problemas (centrados na fonte - 0 impresso) que, na vida científica, não se formulam de forma espontânea, eles são constituídos e possuem sentido. ${ }^{3}$

Conforme Bachelard, as circunstâncias do real estão naturalmente baralhadas e a captura da sua organização é possivel somente ao serem destrinchadas pelos nossos métodos racionais ${ }^{4}$. Ou, conforme Saussure, é o ponto de vista que cria o objeto 5 . Em outros termos, o novo espírito científico propõe a articulação entre racional e real através da construção do objeto de pesquisa, pois somente assim se transforma o objeto social em objeto científico. O "vetor epistemológico", conforme esta perspectiva, indo do racional ao real, tal empreendimento supõe a elaboração de um projeto bem estudado a partir de uma teoria geral, que vai embasar o sistema de hipóteses que constitui a problemática da pesquisa. ${ }^{6}$

Assim, no mundo científico, "a meditação do objeto por parte do sujeito assume sempre a forma de projeto", em que a teoria escolhida materializa-se em métodos, técnicas e procedimentos, constituindo ferramentas capazes de deslindar o fenômeno e suas circunstâncias, naturalmente misturadas. ${ }^{7}$

De acordo com esse enfoque, demonstra-se o real, não se mostra o mesmo, o que supõe a utilização de múltiplos métodos para se apreender o mais possivel a complexidade do objeto, já que é ele quem fornece os elementos à prova - um dos momentos em que é possível mensurar o grau de "realização do racional". ${ }^{8}$

Vale assinalar que essa perspectiva baseia-se na idéia de que não é o ser que ilustra a relação, mas, ao contrário, é "a relação que ilustra o ser", visto que o fenômeno é "um tecido de relações", deve-se valorizar a totalidade, tendo o cuidado para não "tomar degeneração por essência", ao se estabelecerem as múltiplas funções e interações em que o mesmo se constitui. ${ }^{9}$

BACHELARD, Gaston. A formação do espínto científico. Rio de Janeiro: Contraponto, 1996, p. 18.

BACHELARD, Gaston. O novo espirito científico. Porto: Saber, 1986, p. 110.

BOURDEU, Pierre et al. El oficio de sociólogo. 11. ed. México: Veintiuno, 1988.

Idem, p. 14 e 16.

Idem, p. 15.

Idem, p. 13.

Idem, p. 102, 106, 110 e 112. 
Concluindo essas considerações, interessa destacar que o impresso, para ser devidamente explorado, precisa ser questionado a partir de um ponto de vista construído com base na teoria (já que o vetor epistemológico vai do racional ao real), do qual resulta a problemática da pesquisa que, ao ser operacionalizada, transforma-se nos instrumentos utilizados no processo de investigação.

Observa-se ainda que essa percepção não absolutiza a fonte, posto que ela nunca é neutra e tampouco independente ou dissociada das condições que a produzem, nem daquelas que a investigam. Ela fornece apenas os dados que a constituem, dependendo do potencial das ferramentas de pesquisa - a teoria materializada - que instrumentam o pesquisador ao inqueri-la enquanto fonte. Assim, o novo espírito científico tende a relativizar a fonte, a qual assume o seu devido status - o de quem detém os elementos à prova - quando um problema lhe é formulado e o mesmo se articula a uma problemática teórica, suficientemente pertinente a ponto de destrinchar a teia complexa de relações que constitui fenômeno que ela - a fonte - encerra/detém.

\section{3 - A problemática da pesquisa}

Conforme observação feita anteriormente, os comentários a seguir têm 0 intuito de expor as principais condições de produção do discurso científico associadas às pesquisas em andamento sobre impressos, procurando assim apontar alguns elementos que podem contribuir para a construção de um possivel referencial teórico-metodológico, capaz de articular estudos e pesquisas que visam captar a evolução e o significado do impresso, especialmente no decorrer do século XX.

Tais pesquisas se referem ao subprojeto Formação via impresso: do folheto ao computador, ${ }^{10}$ vinculado à linha de pesquisa Formação, Trabalho, Instituição, ${ }^{11} \mathrm{em}$ estreito vínculo com a perspectiva sociológica e a das demais áreas das Ciências Humanas e Sociais, procurando assim minimizar procedimentos que tendem a reduzir ou a anular as especificidades relativas à configuração de objetos relacionados com tal perspectiva.

Entende-se que para se apreender a formação do cidadão através do impresso e as descontinuidades de tal processo, é imprescindivel reconstituir as inúmeras articulações estabelecidas no decorrer do tempo, sustentadas através de relações de disputa pelo poder, desencadeadas entre os agentes dos diversos campos do espaço social, principalmente entre os representantes do campo do poder. ${ }^{12}$

10 O subtítulo - do folheto ao computador - inspira-se no projeto coordenado por CUCUZZA, Héctor Rubén. Historia de la ensiñanza de la lectura y escritura en Argentina: del catón catequístico al ordenador, 1996 (mimeo). Observa-se que tal projeto oferece várias possibilidades de análise comparada com o que está sendo aqui proposto. Tal subprojeto conta com auxilio do Conselho Nacional de Pesquisa (CNPq).

11 Outros projetos vinculados a essa linha de pesquisa: "Formação em escolas católicas, Porto Alegre/RS, 1860-1997"; "Urbanidade e cidadania: processos de formação e de instauração de saberes" (Projeto Integrado - PUCRS, UNISINOS, UFRGS, financiado pelo CNPq e FAPERGS); "Formação construindo competências: os desafios à instituição escolar"; "Formação: um processo múltiplo em formas e parcerias" (FAPERGS e Biblioteca Central/PUCRS).

12 Entre outros referenciais, essa abordagem utiliza-se da análise proposto por Pierre Bourdieu. 
A formação do cidadão é um problema que só no tempo longo pode ser explicado, significando dizer que tais pesquisas são mais promissoras, quando privilegiam a longa duração - uma das dimensões do tempo enquanto categoria de análise - com o intuito de captar a dinâmica do presente e as tendências que nele se constroem, projetando o futuro.

\section{1- O objeto construído sobre impresso}

\section{Hipóteses}

Pretende-se analisar como o impresso estimulou e mesmo garantiu a formação de segmentos populares de Porto Alegre - Estado do Rio Grande do Sul - realizada por representantes da Igreja Católica, no período de 1898 a 1998, ao assegurar o interesse da sociedade em relação a tal empreendimento. Parte-se do pressuposto de que os impressos editados por escolas de ofício católicas ou por iniciativas em apoio a essas entidades foram produzidos no seio de relações de disputa desencadeadas entre os representantes do campo religioso e destes com os demais agentes dos vários campos do espaço social.

Nessa perspectiva, supõe-se que

a o impresso foi elaborado por representantes do campo religioso (ou de outros campos em seu apoio) como um meio pedagógico para, ao exporem suas realizações, bem como as principais necessidades relativas à sua manutenção - em especial, de ordem financeira - a propagação dos princípios básicos da formação instaurados junto a segmentos populares, assim afirmando e estendendo tais fundamentos à comunidade em que estavam inseridos. Isso explica a inclusão no impresso de várias questões em pauta nesse período, principalmente aquelas que se referiam ao jogo de interesses constitutivos da dinâmica estrutural do contexto social, o que aumenta as possibilidades de expansão do poder do campo religioso, já que ao estabelecerem através desse meio os seus principais limites e interesses, balizavam as suas relações de disputa com as demais esferas da sociedade;

- o conjunto de saberes veiculado no impresso instaura novas concepções quanto a vários temas que, de algum modo, relacionam-se com interesses dos representantes do campo religioso. Disso decorrem novas práticas por parte da comunidade que têm repercussão direta na dinâmica de tais escolas. Por isso, destacava-se a importância de cunho pedagógico do impresso para o êxito desse tipo de iniciativa, que visa tornar os formandos que têm freqüentado tais escolas homens "úteis a si, à sua família e à Pátria". Assim, esse veículo constitui efetivamente um meio educativo ao manter vivo o interesse da sociedade como um todo por essas obras, no decorrer das várias décadas de sua existência;

- o impresso constitui uma das formas em que se materializam as relações que foram sendo desencadeadas entre os inúmeros agentes dos vários campos que compõem o espaço social. As crises verificadas na trajetória do campo religioso e, conseqüentemente, nas suas instituições educacionais, estão associadas às suas relações conflitivas com os demais campos sociais do 
contexto de Porto Alegre, o que explica o enfraquecimento desse veículo enquanto meio de formação utilizado pelas escolas de ofício católicas no decorrer do tempo;

- a revitalização das relações entre o campo religioso com os demais campos do espaço social, após os anos noventa, sustenta-se em novas formas de parcerias entre os seus agentes, as quais vêm sendo aglutinadas em torno do Terceiro Setor. O impresso tem contribuido para o fortalecimento de tais parcerias, ao divulgar as estratégias e ações que tendem a se situar no mundo do não-trabalho, procurando assim construir laços de solidariedade social que não dependam direta e exclusivamente do trabalho, já que esta é uma atividade que vem reduzindo a sua centralidade no contexto atual.

\section{Objetivos}

Esse conjunto de objetivos expressa, de forma antecipada, os resultados esperados com a presente pesquisa. Nessa perspectiva, ao analisar as relações que permeiam o sistema de hipóteses exposto anteriormente, pretende-se:

- detectar as várias formas de utilização do impresso enquanto meio de divulgar os princípios básicos da formação instaurada pelos representantes do campo religioso;

- demonstrar a relação entre os assuntos abordados no impresso e as possibilidades de expansão do campo religioso, através desse meio;

- evidenciar que o impresso constitui um veículo duplamente pedagógico: forma filhos de trabalhadores que frequientam as escolas, as quais dispõem das condições necessárias à sua formação, desde que a comunidade que a sustenta seja submetida igualmente a um processo pedagógico, capaz de romper com as suas posturas que tendem a obstaculizar as ações empreendidas por tais instituições. Isso é conquistado, em grande parte, com o auxílio do impresso;

- apontar as novas concepções e práticas sociais sugeridas aos leitores do impresso, que repercutem diretamente no processo de formação de filhos de trabalhadores atendidos pelas instituições escolares investigadas, que pertencem ao campo religioso;

․ associar as dificuldades e/ou o grau de influência da formação via impresso com os períodos de crise nas relações dos representantes do campo religioso entre si e/ou destes com os agentes dos demais campos sociais, em especial com o campo do poder;

- caracterizar as formas de parcerias entre representantes do campo religioso e iniciativa privada, destacando que, após 1990, tais parcerias vêm assumindo novas formas e estratégias de sustentação no tocante à formação, aglutinadas pelo "terceiro setor" e trabalho voluntário. 


\section{4 - Metodologia}

\section{1 - Os pressupostos}

Os pressupostos do referencial teórico que fundamentam a problemática de pesquisa apresentada aqui estão condensados no sistema de hipóteses. A operacionalização dessas referências implica a construção de indicadores que capturem as dimensões dos elementos mais significativos das categorias de análise em que se sustenta essa pesquisa e, assim, identificar um processo estruturado e ao mesmo tempo estruturante, sugerindo os elementos básicos de um processo de formação através do impresso.

Essa é a orientação a ser seguida no decorrer da pesquisa, visando assegurar uma relação dinâmica entre racional e real através da materialização da teoria, com o intuito de explicitar o que não é imediatamente observado. ${ }^{13}$

\subsection{Procedimentos}

\section{Diagrama da problemática da pesquisa}

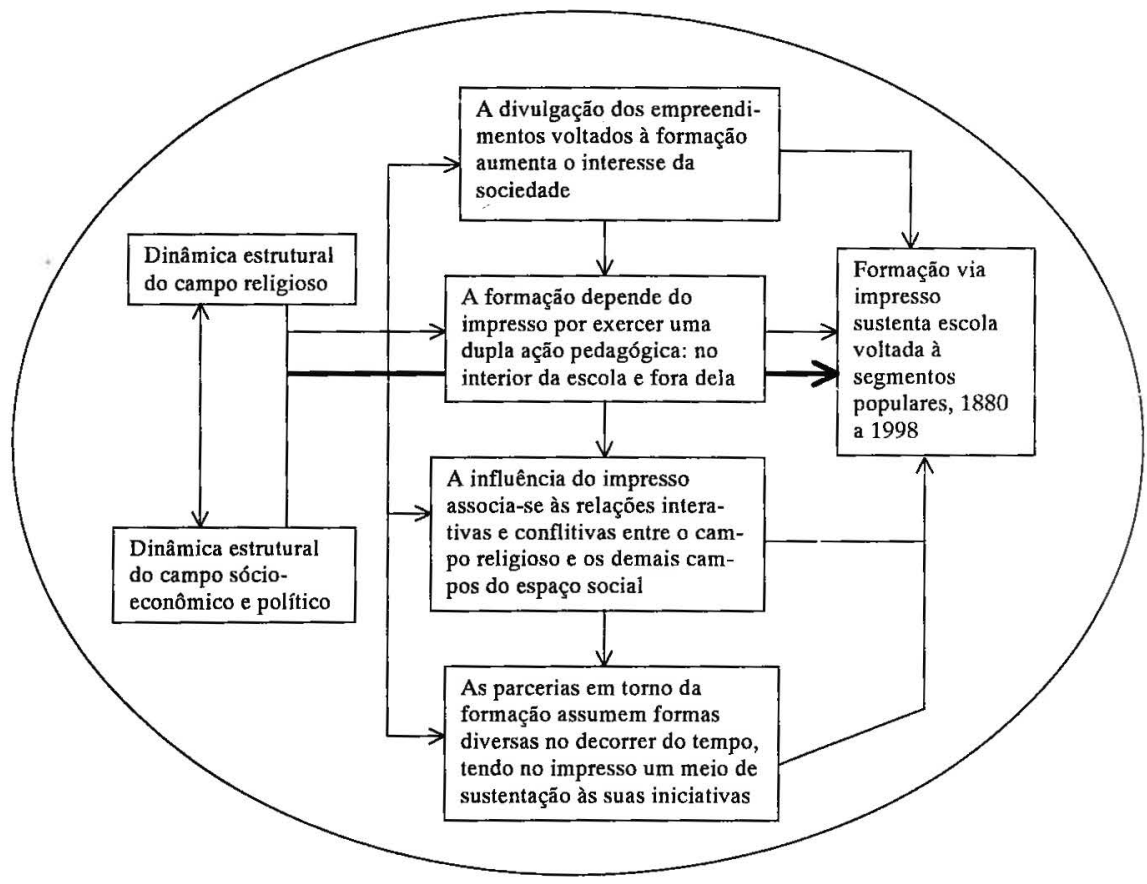

13 Devido à limitação de espaço, o quadro referente à operacionalização das principais categorias de análise não será exposto aqui. 
O esquema apresentado na página anterior expressa as principais relações entre a categoria central - a formação instaurada pelo impresso - e os outros elementos que a explicam e a determinam.

\section{Unidades de pesquisa}

Observa-se que os impressos pesquisados foram produzidos pelas principais iniciativas ligadas ao Terceiro Setor, trabalho voluntário, como também pelas escolas católicas voltadas à formação do cidadão pertencente a segmentos populares, que habitem em Porto Alegre, a partir do final do século passado.

\section{Processamento e acesso aos dados e resultados da pesquisa}

Os dados coletados nesta investigação são processados de acordo com os instrumentos utilizados nos demais subprojetos vinculados à linha mencionada anteriomente. A principal ferramenta é o Folio Views, considerada uma das mais modernas na manipulação de grandes bases de informação, visto que permite que o material seja disponibilizado eletronicamente em um grande Banco de Dados oferecendo uma recuperação muito ágil da informação pelo usuário final, além de viabilizar a adequação das informações, possibilitando um tratamento gráfico uniforme aos documentos, o que também facilita a compreensão dos dados acessados pelo usuário.

\section{5 - Considerações finais}

Os comentários iniciais sobre questões teórico-metodológicas destacam a importância da explicitação das condições de produção do discurso científico, o que implica, em primeiro lugar, anunciar qual é o ponto de vista epistemológico que está sendo utilizado para crivar a(s) fonte(s) privilegiada(s), no caso, o impresso. Isso é fundamental, pois dependendo do "crivo de interpretação que for aplicado", o fenômeno em estudo poderá ter "significações de níveis diferentes". Sendo isio verdadeiro, "uma representação mutilada da 'cifra' (do crivo), condena a uma decifração mutilante". ${ }^{14}$

Em segundo lugar, mas igualmente importante, faz-se necessário explicitar as condições a que a fonte está sendo submetida para se obter os seus registros, ou seja, a fonte só apresenta os conteúdos que a fundamentam, quando inquerida por questões formuladas pelo pesquisador, a partir de um referencial teórico capaz de destrinchar a teia complexa de relações que constitui o fenômeno em análise, tendo na fonte a sua prova. Dai resulta a problemática da pesquisa que, ao ser operacionalizada, materializa-se em método e técnicas que passam - pela sua condição de ferramenta - a instrumentar todo o processo da investigação.

Em outros termos, segundo Panofsky, "os objetos a serem comparados não são obtidos por uma simples apreensão empirica e intuitiva da realidade, mas devem ser conquistados por uma análise metódica e um trabalho de abstração".

14 Concepções de Erwin Panofsky sobre a construção do objeto científico, apresentadas In: BOURDIEU, Pierre. A economia das trocas simbólicas. São Paulo: Perspectiva, 1987, p. 341. 
Ele entende que somente assim poder-se-á "extrair as estruturas que se exprimem e se ocultam nas realidades concretas, sendo então possível estabelecer a comparação destinada a descobrir as propriedades comuns". ${ }^{15}$

Nessa perspectiva, apresentou-se a problemática de pesquisa que fundamenta o subprojeto elaborado para investigar impressos, intitulado Formação via impresso: do folheto ao computador. Parte-se do pressuposto de que a descontinuidade verificada na estrutura e na organização do processo de formação do cidadão, que conta com o impresso enquanto meio pedagógico, assim como os principais saberes instaurados nesse processo, estão associados à dinâmica estrutural do campo religioso (ou de um outro campo social) e à sua articulação, ao mesmo tempo interativa e conflitiva, com a dinâmica estrutural dos demais campos do espaço social, especialmente com o campo do poder (social, econômico e político).

O sistema de hipóteses articulado ao pressuposto teórico referido acima - 0 ponto de vista epistemológico que constitui o crivo para investigar o impresso inicia o seu processo de operacionalização com os objetivos formulados e, a seguir, materializa-se em conceitos e respectivas dimensões, indicadores e técnicas a serem utilizados ao instigar as principais categorias de análise privilegiađas na pesquisa.

Também, fazem-se referências aos demais procedimentos concernentes a tal investigação. Desse modo, espera-se atingir o rigor científico desejado ao se realizar um empreendimento que é de interesse de toda a sociedade. Nesse sentido, é importante instaurar rupturas em toda e qualquer concepção que dissocia o tempo das dimensões que o constituem, tais como memória, relação, invenção, construção, movimento, mudança... Até porque isso é uma condição para se falar em ética, em liberdade, em cidadania.

Assim, espera-se reduzir as chances de ratificação do senso comum pela pseudociência, o qual assume o status de postulado científico, tranformando-se em obstáculo epistemológico ainda mais resistente. E sabe-se que é sempre mais difícil romper com uma "moral disfarçada em ciência", por se apresentar como um conhecimento dito científico. ${ }^{16}$

15 Idem, p. 338 e 339.

16 BOURDIEU, Pierre. Coisas ditas. São Paulo: Brasiliense, 1990, p. 40. 